\title{
Toddler with repeated fall frequently visiting hospital presented with acute subdural hematoma on readmission with ultra-rapid evolution: surgical management strategy
}

\author{
Guru Dutta Satyarthee ${ }^{1}$ \\ 1 Department of Neurosurgery, Neurosciences Centre, AlIMS New \\ Delhi, INDIA
}

\begin{abstract}
Repetitive fall producing head injury in children may lead to development of intracranial hematoma. The course of evolution may be rapid in case of repeated fall due to induction of sub-clinical coagulopathy caused by repetitive cranial injury. The awareness of such possibility is highly desired among the pediatrician and neurosurgeon and emergency team and quick diagnosis and pertinent imaging study is of immense value and appropriate surgical management for prompt and expediting the evacuation of intracranial hematoma evacuation should be attempted to preserve good neurological outcome. Authors reports a case, who had rapid neurological worsening, managed surgically with good neurological outcome, further various surgical management options along with pertinent literature are briefly reviewed.
\end{abstract}

\section{INTRODUCTION}

Traumatic brain injury is a global epidemic affecting all age group and producing cognitive, emotional, psychological, and economic burden and various disability and huge cost to society on care of acute phase of head injury extending to the rehabilitative phase. Author presents a case, who had repeated fall in house due to carelessness and previously also visited hospital for fall, at current admission had rapid neurological worsening due to acute subdural hematoma. He was managed successfully.

\section{CASE ILLUSTRATION}

Author presents a case of two- year old male child with history of repeated falls. Patient had fall from first floor with loss of consciousness. Patient presented to trauma emergency, on evaluation GCS was E4V5M6 with no focal neurological deficit. Computed tomography head did not reveal presence of fracture or intracranial haematoma and discharged satisfactorily after observation. (Fig-1) However, due carelessness of parents, the child had again fell down and brought to emergency in unconscious state after three days after discharge from hospital following previous admission. On examination at current admission, vitals were stable with GCS was E3V3M5. His

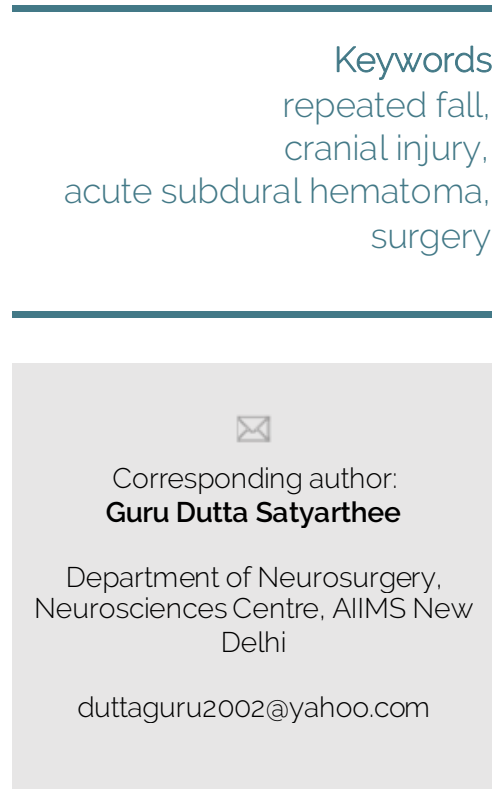

Copyright and usage. This is an Open Access article, distributed under the tems of the Creative Commons Attribution Non-Commercial No Derivatives License (https://creativecommons .org/licenses/by-nc-nd/4.0/) which permits noncommercial re-use, distribution, and reproduction in any medium, provided the original work is unaltered and is properly cited.

The written permission of the Romanian Society of Neurosurgery must be obtained for commercial re-use or in order to create a derivative work.

ISSN online 2344-4959

(C) Romanian Society of Neurosurgery

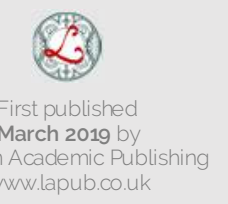


pupils were asymmetric, left pupil was dilated and not reacting to light. Urgent repeat computed tomography scan head was done, showed presence of acute subdural hematoma extending over the left frontotemporal with midline shift with subfalcine herniation. (Fig-2). Baby had further neurological deterioration while awaiting admission at emergency to E2V2M4 and hence taken up for emergency surgical evacuation of acute SDH under general anaesthesia. dura was tense and following

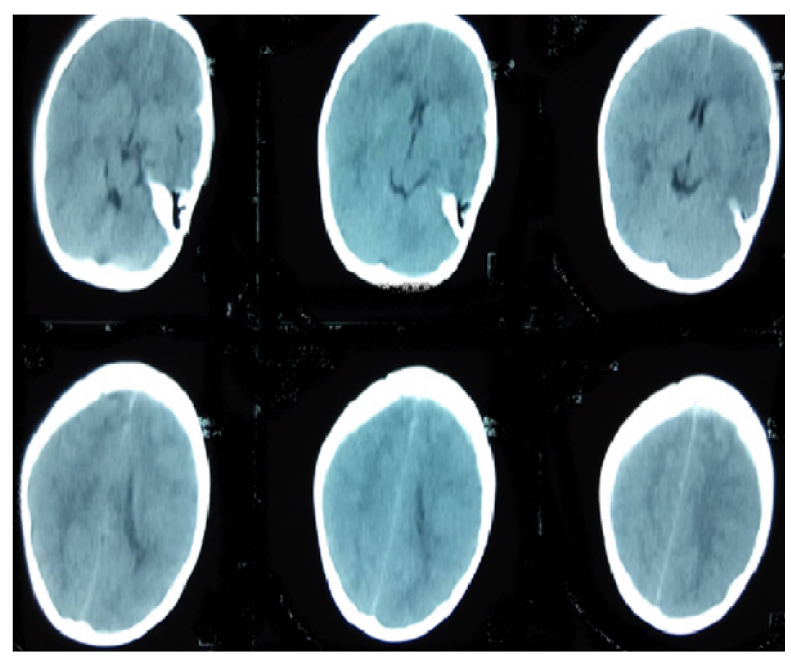

FIGURE 1. Cranial computed tomography scan following fall at previous admission showing no evidence of fracture or presence of extra-axial or intra-axial hematoma.

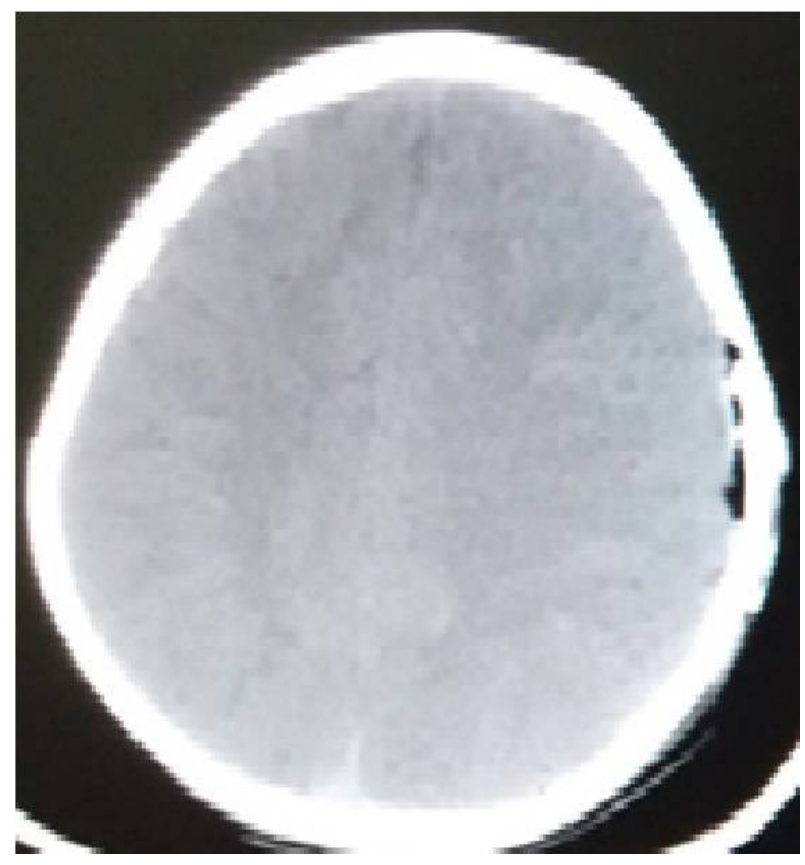

FIGURE 1. Non contrast computed tomography after six months following surgical evacuation of acute subdural hematoma. opening the dura, thick dark coloured blood clot was observed in the subdural space. Post operatively child was electively ventilated for two days and then extubated and continued to receive decongestant therapy, antibiotics and antiepileptic medication continued. Following emergency evacuation of acute subdural hematoma, pupil anomaly improved. At the time of discharge, child was E4V5M6, accepting orally and playing actively with mother.

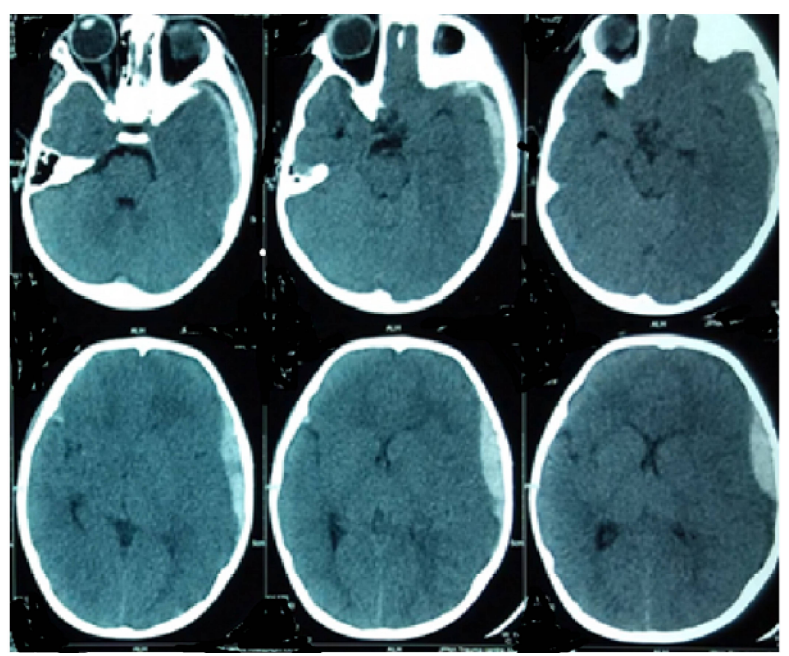

FIGURE 2. Computed tomography showing presence of large acute subdural hematoma over left fronto- temporal region with associated mass effect and subfalcine herniation, at current admission.

\section{DISCUSSION}

Traumatic brain injury constitutes leading causes of acquired disability and death in the infants as well as children ${ }^{1}$. Subdural hematoma is most common intracranial pathology observed in neurosurgical practice following traumatic brain injury ${ }^{2,3}$.

Falls and motor vehicle accidents are common non-inflicted causes, while child abuse among infants and young children are unfortunate inflicted causes of traumatic brain injury ${ }^{2}$. The pathomechanism of fall from a short height in the very young children impart a predominantly linear force to the head. These forces can cause local deformity of skull or in cases forces being sufficient enough to produce skull fractures, and extradural hematomas. Subdural hematomas development commonly results from displacement of the brain relative to the dura, and may associated with rupture of the bridging veins courses from the brain's surface to the overlying larger draining venous sinuses ${ }^{4,5}$. However, extradural hematomas is commonly associated with 
focal impact injuries, but subdural hematoma almost always results from angular head deceleration, in which the brain continues to rotate relative to the more stationary skull and dura, associated with diffuse parenchymal damage. Management of traumatic brain injury primary aims for limiting the progression of the primary brain injury and minimizing secondary brain injury ${ }^{6-11}$.

Surgical management is the mainstay of management of acute subdural hematoma with mass effect. However, in acses with rapid neurological deterioration, surgical decompression needs to be expedited and, in many resource, scarce centre, operation theatre may not be available, larger burr hole craniostomy with evacuation of subdural hematoma with subdural drain placement can offer an option with burr hole being placed at the site of thickest component ${ }^{9,11}$.

Satyarthee et al. reported burrhole evacuation of acute subdural haematoma is considered as a novel technique to reverse the worsening neurological state of patient ${ }^{7,8}$.

Other traditional approach include craniotomy with evacuation of subdural hematoma, decompressive craniectomay and management of associated intracerebral hematoma. Decompressive craniectomy or other major intracranial procedure for evacuation of acute subdural hematoma can be done if patient GCS and neurological status remains stable ${ }^{8-13}$.

\section{CONCLUSION}

A child with repeated fall may develop larger haematoma, although previous cranial CT scan may not show presence of any intracranial hematoma, and depending on history, detailed clinical assessment, appropriate neuroimaging study is advocated and further early and rapid neurological deterioration, emergent surgical management is must. Awareness of rare but important pathology is highly recommended for pediatrician, neurologist, neurosurgeon and emergency care team.

\section{REFERENCES}

1. Parslow RC, Morris KP, Tasker RC, Forsyth RJ, Hawley CA. UK peadiatric traumatic brain injury study steering group, epidemiology of traumatic brain injury in children receiving intensive care in the UK. Arch Dis Child 2005; 90:1182-7

2. Ewing-Cobbs L, Prasad M, Kramer L, Louis PT, Baumgartner J, Fletcher JM, et al. Acute neuroradiologic findings in young children with inflicted or noninflicted traumatic brain injury. Childs Nerv Syst 2000; 16:25-33

3. Vinchon $M$, Defoort-Dhellemmes $S$, Desurmont $M$, Dhellemmes P. Accidental and nonaccidental head injuries in infants: A prospective study.J Neurosurg 2005; 102:3804.

4. Meservy CJ, Towbin R, McLaurin RL, Myers PA, Ball W. Radiographic characteristics of skull fractures resulting from child abuse. AJR Am J Roentgenol 1987; 149:173-5.

5. Vance BM. Ruptures of surface blood vessels on cerebral hemispheres as a cause of subdural hemorrhage. AMA Arch Surg 1950; 61:992-1006

6. Gennarelli TA, Thibault LE. Biomechanics of head injury. In: Wilkins RH, Rengachary SS, editors. Neurosurgery. 1 st ed. New York: McGraw Hilb; 1985. p. 1531-36.

7. Satyarthee GD, Chouksey P., Singh P., Agrawal D, Gurjar H. Emergent burr-hole drainage of traumatic acute subdural haematoma with drain placement in pre-existing coagulopathy showing rapid neurological deterioration: $\mathrm{A}$ novel technique, Indian J Neurotrauma 2015;12:19-22

8. Motohashi O: Single burr hole evacuation of traumatic ASDH of posterior fossa in emergency room, J Neurotrauma. 2002; 19:993-938.

9. Youichi Yanagawa, Toshihisa Sakamoto: Results of Single Burr Hole Drainage for Acute Subdural Hematoma with Non-Reactive Pupil. Turk Neurosurg 2012; 22(2):196-9.

10. Sinha S, Raheja A, Garg M, Moorthy S, Agrawal D, Gupta DK, Satyarthee GD, Singh PK, Borkar SA, Gurjar H, Tandon V, Pandey RM, Sharma BS. Decompressive craniectomy in traumatic brain injury: A single-center, multivariate analysis of 1,236 patients at a tertiary care hospital in India. Neurol India. $2015 ; 63(2): 175-83$.

11. Alvis-Miranda HR, M Rubiano A, Agrawal A, Rojas A, Moscote-Salazar LR, Satyarthee GD, Calderon-MirandaWG, Hernandez NE, Zabaleta-Churio N. Craniocerebral Gunshot Injuries; A Review of the Current Literature Bull Emerg Trauma 2016; 4 (2) 65-74

12. Verma SK, Borkar SA, Singh PK, Tandon V, Gurjar HK, Sinha S, Satyarthee GD, Gupta D, Agarwal D, Sharma BS. Traumatic Posterior Fossa Extradural Hematoma: Experience at Level I Trauma Center. Asian J Neurosurg. 2018 Apr-Jun;13(2):227-232.

13. Satyarthee GD. Ideally, How Early Should Cranioplasty Be Performed-Days, Weeks, or Months Following Decompressive Craniectomy Surgery to Label as "Optimal Early Cranioplasty"? Big Enigma. World Neurosurg. 2018; 112:302-303. 